\title{
The Shredding Test and Simulation of Steel-plate of Scrap Automobile
}

\author{
$\mathrm{Xu}$ Cunshan \\ Henan Polytechnic Institute \\ Nanyang, 473009, China
}

\begin{abstract}
The shredding test and simulation of steel-plate of scrap automobile are mentioned in this text. The result of experiment and simulation are compared. The situation of experiment and attaining the simulation result by the postprocessor program of ANSYS has found a reliable analysis method. The engineering software of ANSYS/ LS-DYNA is used to simulate.
\end{abstract}

Keywords-Computer Simulation, Metal Fracture, Steel-plate of Scrap automobile

\section{PREFACE}

With the rapid development of auto industry, automobiles began to pour into the ordinary families, and there will be a lot of scrap car in one or two decades. In China, the processing method of recycling steel-plate of scrap car now still lags behind, in the manual operation for a long period. The dismantled parts such as shell, which shall not be used again, will be processed through flame cutting, dropping hammer, and blasting method, etc. The manual operation method has such many shortcomings as bad working conditions, low productivity, heavy labor and serious pollution, and also cannot meet the demand in this respect in the future. ${ }^{[1]}$ In order to adapt to the large demand for recycling steel in China in the future, we must raise the mechanization of processing waste steel. So it is very necessary to independently produce large scrap car extrusion crusher in our country. This author based on experiment uses nonlinear finite element software ANSYS/ LS-DYNA to simulate the broking process of steel recycling of scrap car to make research of the related broken contents.

This paper researches the case in which a metal is knocked on by a broken hammer head at a certain initial velocity. In the research process of the related broking theory, we only know the initial movement speed of the hammer body and the constraint conditions of the metal to be broken, but do not know the law and size of the bump load between hammer body and the metal to be broken, and this process also involves many nonlinear problems. Under the effect of bump stroke, collision damage and destruction process is complicated nonlinear dynamic response process, which includes the geometric nonlinearity caused by the large structure displacement, the physical nonlinearity (material nonlinear) represented by the massive material displacement, the serious movement nonlinearity, and the complex contact and friction problems. This brings some difficulty to the theory study of broking problem. The theoretical research of impact phenomenon is mainly based on Hertz's standard static contact theory or the related experimental research. For the impact problem of deformation, the finite element analysis method is mostly used. With the development of the computer, finite element analysis will be used more widely in analysing engineering impact problems and analogue computation. [2-5]

For the low speed for the large deformation discussed in this paper, the dynamic equation of nonlinear problems is:

$$
\mathrm{Mu}+\mathrm{Cu}+\mathrm{F}_{\text {int }}=\mathrm{F}_{\text {ext }}
$$

In the equation $\mathrm{F}_{\text {int }}$ is internal force vector, and it is the nonlinear function of displacement $\mathrm{u} ; \mathrm{F}_{\text {ext }}$ is external force vector; $\ddot{u}$ and $\dot{u}$ are respectively the acceleration of node and speed vector; $\mathrm{M}$ and $\mathrm{C}$ are respectively mass matrix and damping matrix.

In ANSYS/ LS-DYNA, the solution to Equation (1) mainly uses central difference method - a kind of explicit solution. This method does not need iteration, and if the mass matrix is diagonalized, it don't need to inverse matrix. Note that the explicit solution is conditional stability, but as long as the time step is less than critical step, you'll get a stable solution. The form of the displacement representing the acceleration, its central difference formula is:

$$
\mathrm{d}^{\mathrm{n}}=\alpha^{\mathrm{n}}=\left(\frac{\Delta \mathrm{t}^{\mathrm{n}-\frac{1}{2}}\left(\mathrm{~d}^{\mathrm{n}+1}-\mathrm{d}^{\mathrm{n}} /-\Delta \mathrm{t}^{\mathrm{n}-\frac{1}{2}} / \mathrm{d}^{\mathrm{n}}-\mathrm{d}^{\mathrm{n}-1}\right)}{\Delta \mathrm{t}^{\mathrm{n}-\frac{1}{2}}-\Delta \mathrm{t}^{\mathrm{n}} \Delta \mathrm{t}^{\mathrm{n}-\frac{1}{2}}}\right)
$$

Here through the known conditions, we may use the formula $\alpha^{n}=n^{-1}\left(\boldsymbol{r}^{n}-\mathrm{C}^{\text {damy }} v^{n-\frac{2}{n}}\right)$, to seek out $\alpha^{\mathrm{n}}$, and use formula (2) to seek out $\mathrm{d}^{\mathrm{n}+1}$, and finally we can seek out the responding strain and stress.

\section{IMPACT EXPERIMENT AND THE RESULTS}

Impact experiments can be used to better understand the crushing mechanism of metal, and the experiment can be used to simulate, and the experimental results can be used to verify the reliability of the simulation analysis, which can bring about a more feasible simulation method used for simulation analysis of recycling steel broken of scrap car. This experiment based on the original 58.84/29.42J impact test enginery, through the appropriate transformation is completed. The experiment content is mainly composed of a set of hammer heads with different quality amount and recycling steel taken 
from two kinds of models of discarded automobiles, and the sample size and material mechanics performance are shown in table 1 , the result of the test reaches the expected effect.

The broken results of test sample by the impact of different mass of hammer heads at different speed are shown in Table 2:

The upper left of Figure 1 is the broking result of the first group of test sample impacted by the hammer head with mass of $5.33 \mathrm{~kg}$, at $3.67 \mathrm{~m} / \mathrm{s}$. Seen from the graph, the test sample has been impacted out a triangular slit with a about $0.5 \mathrm{~mm}^{2}$. The upper right of Figure 1 is the broking result of the first group of test sample impacted by the hammer head with mass of $6.88 \mathrm{~kg}$, at $3.75 \mathrm{~m} / \mathrm{s}$. From the graph, the test sample has been impacted out a much bigger slit with a about $2.5 \mathrm{~mm}^{2}$. The left lower part of Figure 1 is the broking result of the second group of test sample impacted by the hammer head with mass of $8.9 \mathrm{~kg}$, at $3.83 \mathrm{~m} / \mathrm{s}$, and the slit is about $3.5 \mathrm{~mm}^{2}$. The right lower part of Figure 1 is the broking result of the second group of test sample impacted by the hammer head with mass of $8.9 \mathrm{~kg}$, at $3.83 \mathrm{~m} / \mathrm{s}$, and the test sample has been broken down completely.

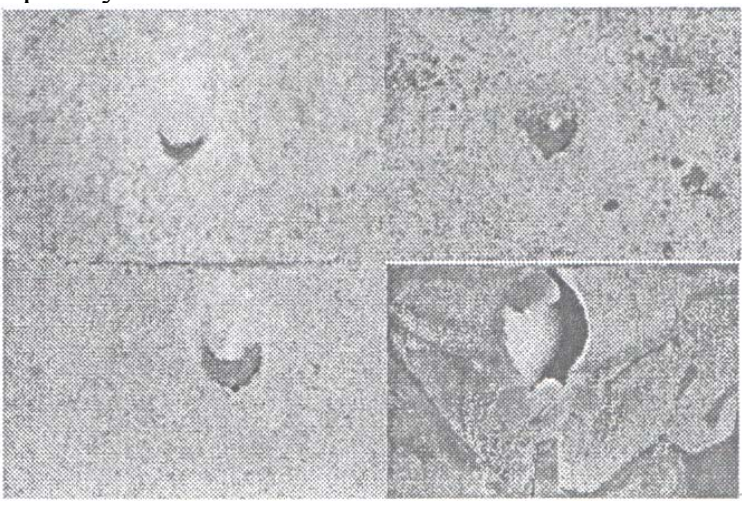

Figure 1 The shredding station of test

From this trial results it can be seen that with the increase in hammer mass and speed, the bursting area of the sample also significantly is enlarged; with the increase in specimen thickness, its fracture area is reduced.

\section{STIMULATION ANALYSIS AND THE RESULTS[6-8]}

In this paper the simulation is carried out in ANSYS/LS-DYNA software. ANSYS/LS-DYNA is fully functional geometry nonlinear, material nonlinear, friction and contact and separating interface state nonlinear finite element numerical calculation software. It mainly contains Lagrange algorithm with ALE and Euler algorithm; Explicit solution is given priority to, with implicit solving function. All relevant problems such as contact-collision, explosion, wear armor and penetration, stress wave transmission, metal processing, fluid solid coupling, can be solved with ANSYS/ LS-DYNA.

\section{A. Finite element model}

The finite element model of the simulation is shown in Figure 2:

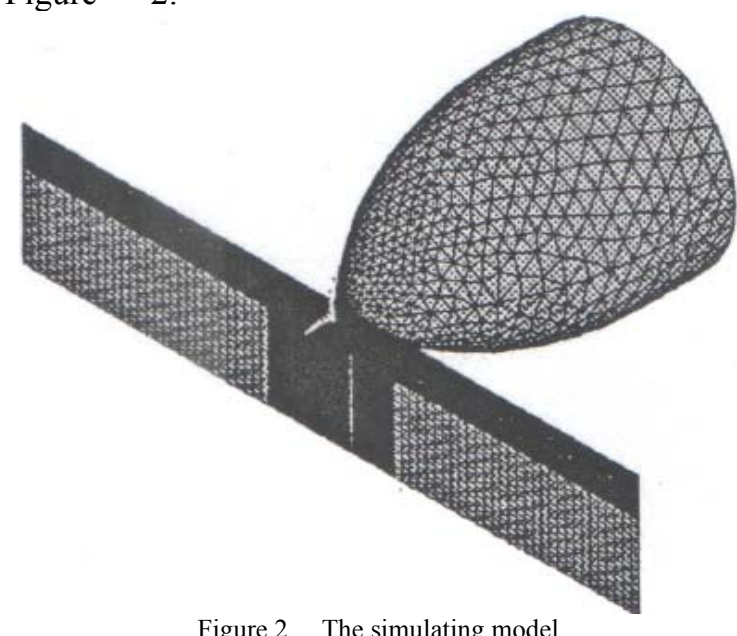

The hammer head in the figure is SOLID164 unit, and SOLID164 is a 8-nodes unit. In order to reduce calculation timing, reductions (single point) integral is often used, but it easily causes the hourglass mode, so in analysis HOURGLASS CTRLS and BULK VISCOSITY options need to be used to control hourglass, and it is used to simulate the $3 \mathrm{~d}$ entity unit, and its degree of freedom have UX, UY UZ, VX, VY, VZ, AX, AY, AZ. Using SOLID 164 unit can ues most of the materials model in LS-DYNA. Recycling steel-plate is SHELL163 units, and SHELL163 is four nodes shell unit, and this unit in each node has twelve degree of freedom, is respectively: UX, UY UZ, and VX, VY, VZ, AX, AY, AZ, ROTX, ROTY, ROTZ, and the unit formula is single point accumulation Belytschko-Tsay by default. This integral formula can reduce calculation time, improve the calculation efficiency.

Because in this paper the ultimate tensile strength of hammer head is $\sigma_{\mathrm{b}}=1200 \mathrm{MPa}$, and the test sample's is $\sigma_{\mathrm{b}}=375 \sim 410 \mathrm{MPa}$, in contrast, hammer head can be considered a rigid material model, and sample chooses nonlinear dynamic model with strengthening plastic material, and the materials parameters used in this chapter is shown in Table 3:

\section{B. Analysis results}

Corresponding to the shredding station of test, The simulating model and the results of simulation are respectively as shown in figure 2 and figure 3 below.

From the results of simulation it can be seen that the simulation results of the two groups of test samples are better corresponding with the experimental results, and the breakdown area is close to the bursting area in experiments. But analysis is completed through discrete finite element method, and the split shape and practical situation are different. The simulation results gap has no 
curly side and doesn't appear the shape of the inverted triangle, because in the finite element simulation model is composed of limited discrete units, and in fact metal is made from many tiny crystals. In the process of simulation, the divided unit represents the composition of the material, and because of the limit of the realistic conditions unit cannot be divided into small enough to be close with the crystal. In the program ANSYS/LS-DYNA, the processing method of failure units is to delete them. The three points above are the main reasons for the slit shape differences between the simulation and experiment, and also an inevitable problem with finite element analysis method.

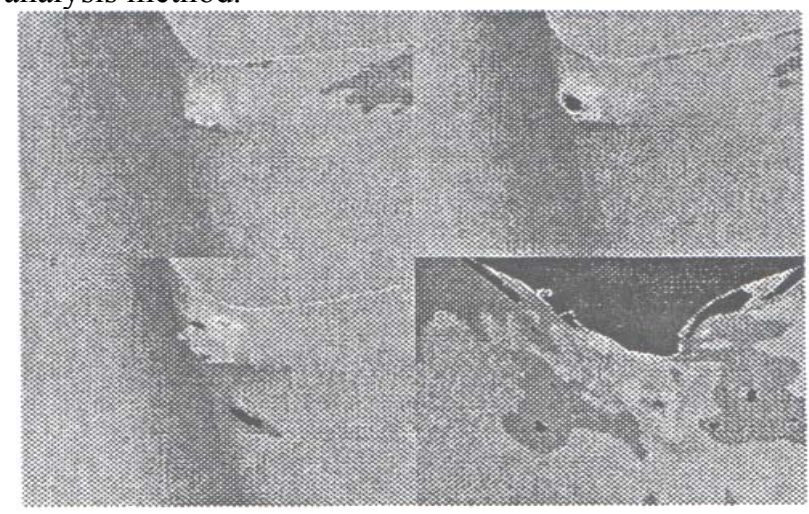

Figure 3. The results of simulating

\section{CONCLUSION}

The main research contents of this paper: having reformed the standard 58.84/29.42 J impact test enginery and completed crushing test; having calculated the hammer head mass, hammering speed and impact energy; using ANSYS/LS-DYNA nonlinear analysis software to have fulfilled simulation analysis after properly simplifying the real situation of the experiment, and according to the simulation results, it is concluded that the chosen unit type and material model successfully simulate the real situation, and they can be used for breaking simulation of recycling steel of scrap car.

\section{REFERENCES}

[1] Liu Jianxiong, Liu Jun. The Emerging Fragment and Separation Technology of Scrap Steel [J]. Metallurgical Equipment, 2001.10 (18-21)

[2] Ma Xiaoqing, Han Feng. High-speed Impact Dynamics [M]. Defense Industry Press, 1998

[3] Ted Belytschko, Wing Kam Liu, Brian Moran. (Zhuang Zhuo, translator). The Continuum and the Nonlinear Finite Element of Structure. [M]. Tsinghua University Press, 2002

[4] Lv Hexiang, Jiang Heyang. The Nonlinear Finite Element [M]. Chemical Industry Press, 1991.

[5] Song TianXia. The Finite Element Calculation of Nonlinear Structure [M]. The Press of Huazhong University of Science and Technology, 1996.

[6] Bai Jinze. LS-DYNA3D Theoretical Basis and Example Analysis [M]. Science Press, 2005

[7] Shi Dangyong, Li YuChun. The Explicit Dynamic Analysis Based on ANSYS/LS-DYNA 8.1 [M]. Tsinghua University Press, 2005

[8] ANSYS RELEASE 7.0 /Help/ANSYS Help ANSYS LS-DYNA User's Guide.

TABLE I INDICATES THE DIMENSION OF THE TEST SAMPLE AND THE MATERIAL'S MECHANICS CAPABILITY.

\begin{tabular}{|c|c|c|c|c|c|c|c|}
\hline number & \multicolumn{3}{|c|}{$\begin{array}{c}\text { Size }(\mathrm{mm}) \\
(\text { length } \times \text { width } \times \text { height })\end{array}$} & \multicolumn{2}{|l|}{$\begin{array}{l}\text { Yield Limit } \\
\sigma_{a}(\mathrm{MPa})\end{array}$} & \multicolumn{2}{|c|}{$\begin{array}{c}\text { Intensity limit } \sigma_{\mathrm{b}} \\
(\mathrm{MPa})\end{array}$} \\
\hline $1 \#$ & \multicolumn{3}{|c|}{$153 \times 60 \times 1.3$} & \multicolumn{2}{|l|}{$175 \sim 205$} & \multicolumn{2}{|c|}{$295 \sim 375$} \\
\hline $2 \#$ & \multicolumn{3}{|c|}{$153 \times 60 \times 0.9$} & \multicolumn{2}{|l|}{$205 \sim 245$} & \multicolumn{2}{|c|}{$355 \sim 410$} \\
\hline \multicolumn{8}{|c|}{ TABLE II THE HAMMERHEAD'S PARAMETERS } \\
\hline number & \multicolumn{3}{|c|}{ impact hammer mass $(\mathrm{kg})$} & \multicolumn{2}{|c|}{$\begin{array}{c}\text { broking speed } \\
(\mathbf{m} / \mathbf{s})\end{array}$} & \multicolumn{2}{|c|}{ ork done by impact $(\mathrm{J}$} \\
\hline 1 & \multicolumn{3}{|c|}{5.33} & \multicolumn{2}{|l|}{3.66} & \multicolumn{2}{|c|}{35.68} \\
\hline 2 & \multicolumn{3}{|c|}{6.88} & \multicolumn{2}{|l|}{3.75} & \multicolumn{2}{|c|}{48.42} \\
\hline 3 & \multicolumn{3}{|c|}{8.90} & 3.83 & & \multicolumn{2}{|c|}{65.35} \\
\hline \multicolumn{8}{|c|}{ TERS OF ANALYSIS MOD } \\
\hline Name & $\begin{array}{l}\text { Density } \\
\left(\mathrm{kg} / \mathrm{m}^{3}\right)\end{array}$ & $\begin{array}{l}\text { Elastic } \\
\text { modulus } \\
(\mathrm{GPa})\end{array}$ & $\begin{array}{l}\text { Poisson's } \\
\text { ratio }\end{array}$ & $\begin{array}{l}\text { Yield limit } \\
\text { (MPa) }\end{array}$ & $\begin{array}{c}\text { Tangent } \\
\text { modulus } \\
(\mathrm{MPa})\end{array}$ & $\begin{array}{c}\text { Intensity } \\
\text { limit } \\
\text { (MPa) }\end{array}$ & $\begin{array}{l}\text { Failure } \\
\text { strain }\end{array}$ \\
\hline $\begin{array}{l}\text { hammer } \\
\text { head }\end{array}$ & 7850 & 206 & 0.3 & - & - & 1200 & - \\
\hline $1 \#$ & 7850 & 200 & 0.28 & 205 & $700^{[10]}$ & 375 & 0.82 \\
\hline $2 \#$ & 7850 & 200 & 0.28 & 245 & 700 & 410 & 0.8 \\
\hline
\end{tabular}

